\title{
Novel condylar repositioning method for 3D-printed models
}

\author{
Keisuke Sugahara ${ }^{1,2^{*}}$ (D), Yoshiharu Katsumi ${ }^{1}$, Masahide Koyachi ${ }^{1}$, Yu Koyama', Satoru Matsunaga ${ }^{2,3}$, Kento Odaka ${ }^{3}$, \\ Shinichi $\mathrm{Abe}^{3}$, Masayuki Takano ${ }^{4}$ and Akira Katakura ${ }^{1,2}$
}

\begin{abstract}
Background: Along with the advances in technology of three-dimensional (3D) printer, it became a possible to make more precise patient-specific 3D model in the various fields including oral and maxillofacial surgery. When creating 3D models of the mandible and maxilla, it is easier to make a single unit with a fused temporomandibular joint, though this results in poor operability of the model. However, while models created with a separate mandible and maxilla have operability, it can be difficult to fully restore the position of the condylar after simulation. The purpose of this study is to introduce and asses the novel condylar repositioning method in 3D model preoperational simulation.
\end{abstract}

Methods: Our novel condylar repositioning method is simple to apply two irregularities in 3D models. Three oral surgeons measured and evaluated one linear distance and two angles in 3D models.

Results: This study included two patients who underwent sagittal split ramus osteotomy (SSRO) and two benign tumor patients who underwent segmental mandibulectomy and immediate reconstruction. For each SSRO case, the mandibular condyles were designed to be convex and the glenoid cavities were designed to be concave. For the benign tumor cases, the margins on the resection side, including the joint portions, were designed to be convex, and the resection margin was designed to be concave. The distance from the mandibular ramus to the tip of the maxillary canine, the angle created by joining the inferior edge of the orbit to the tip of the maxillary canine and the ramus, the angle created by the lines from the base of the mentum to the endpoint of the condyle, and the angle between the most lateral point of the condyle and the most medial point of the condyle were measured before and after simulations. Near-complete matches were observed for all items measured before and after model simulations of surgery in all jaw deformity and reconstruction cases.

Conclusions: We demonstrated that 3D models manufactured using our method can be applied to simulations and fully restore the position of the condyle without the need for special devices.

Keywords: Three-dimensional models, Condylar repositioning, Tumor resection, Orthognathic surgery

\section{Background}

In the field of oral and maxillofacial surgery, many institutions have recently begun using three-dimensional (3D) printers to create 3D models of a variety of diseases. The first medical fabrication laboratory in Japan was established at Tokyo Dental College-the "Fab Lab TDC"-in December 2013 [1]. Techniques to construct full-scale 3D models, such as of the jaw, based on computed tomography

\footnotetext{
* Correspondence: ksugahara@tdc.ac.jp

${ }^{1}$ Department of Oral Pathobiological Science and Surgery, Tokyo Dental College, 2-9-18 Kanda Misaki-cho, Chiyoda-ku, Tokyo, Japan

${ }^{2}$ Oral Health Science Center, Tokyo Dental College, 2-9-18 Kanda Misaki-cho,

Chiyoda-ku, Tokyo, Japan

Full list of author information is available at the end of the article
}

(CT) and magnetic resonance imaging (MRI) modalities have been reported recently [1-3]. We have also created preoperative 3D-printed models of cases for tumors in maxilla and mandible, jaw deformities, and used them primarily consultation to patients and for preoperative simulations.

When creating 3D models of the mandible and maxilla, it is easier to make a single unit with a fused temporomandibular joint, though this results in poor operability of the model and when bending reconstructive plates. However, while models created with a separate mandible and maxilla have good operability, it can be difficult to fully restore the position of the mandibular condyle after simulations. To 
fully restore the position of the condyle, methods have been reported that include the manufacture of a device to maintain the configuration of the mandible and embedding of magnets into the joint [3].

Here, we report a novel method we developed to fully restore the position of the condyle that does not require any device other than the $3 \mathrm{D}$ model. We also examined the reproducibility of the method.

\section{Methods}

\section{Subjects}

This study included two patients who underwent sagittal split ramus osteotomy (SSRO) and two benign mandibular tumor patients who underwent segmental mandibulectomy and immediate reconstruction. The study was approved by the ethics committee of Tokyo Dental College (No. 646) (Tokyo, Japan).

\section{Methods}

Image data of the maxilla, mandible, and lesions were reconstructed from CT image data using Mimics ${ }^{\oplus}$ (Materialise, Leuven, Belgium). Our novel condylar repositioning method is simple to apply two irregularities in 3D models. For each SSRO case, the mandibular condyles were designed to be convex and the glenoid cavities were designed to be concave using 3-Matic ${ }^{\oplus}$ (Materialise, Leuven, Belgium) (Fig. $1 \mathrm{a}-\mathrm{c}$ ). For the mandibular tumor cases, the margins on the resection side, including the joint portions, were designed to be convex, and the resection margin was designed to be concave using 3 -matic ${ }^{\bullet}$. 3D models were created using OBJET Connex $260^{\circ}$ (Staratasys, MI) (Fig. 1d).

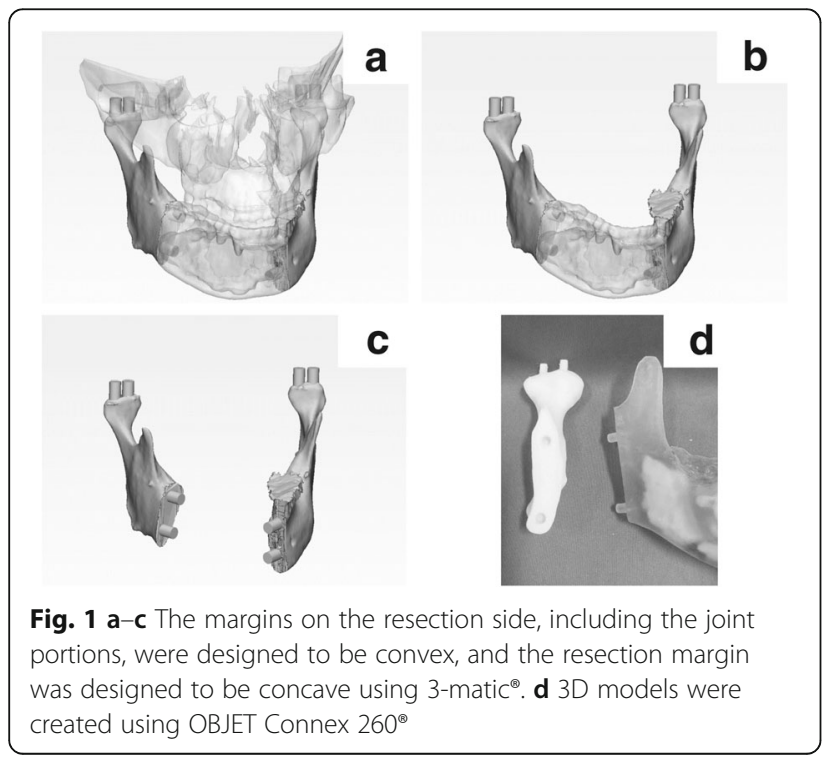

\section{Measurements}

The distance from the mandibular ramus to the tip of the maxillary canine, the angle created by joining the inferior edge of the orbit (Or) to the tip of the maxillary canine and the ramus, the angle created by the lines from the base of the mentum (Me) to the endpoint of the condyle $(\mathrm{CE})$, and the angle between the most lateral point of the condyle (LC) and the most medial point of the condyle (MC) [4] were measured before and after simulations by three certified oral surgeons (Fig. $2 \mathrm{a}-\mathrm{c}$ ).

\section{Results}

Evaluation of the length and angle (Table 1)

For all four cases, the mean values of each item measured by the three oral surgeons were calculated before and after model operations. Only the affected side of the reconstruction cases was measured.

\section{Length of the ramus to the maxillary canine}

The distances from the anterior edge of the ramus to the canine before and after model simulations of surgery matched completely in all four cases.

\section{Canine-orbitale and ramus-canine angles}

The canine-orbitale and ramus-canine angles before and after simulations matched completely in three cases. A decrease of $0.5^{\circ}$ was observed in case 3 (mandibular tumor patient).

\section{Me-CE and LC-MC angles}

The Me-CE and LC-MC angles before and after model simulations of surgery matched completely in all four cases.

Near-complete matches were observed for all items measured before and after model simulations for surgery in all jaw deformity and reconstruction cases. These

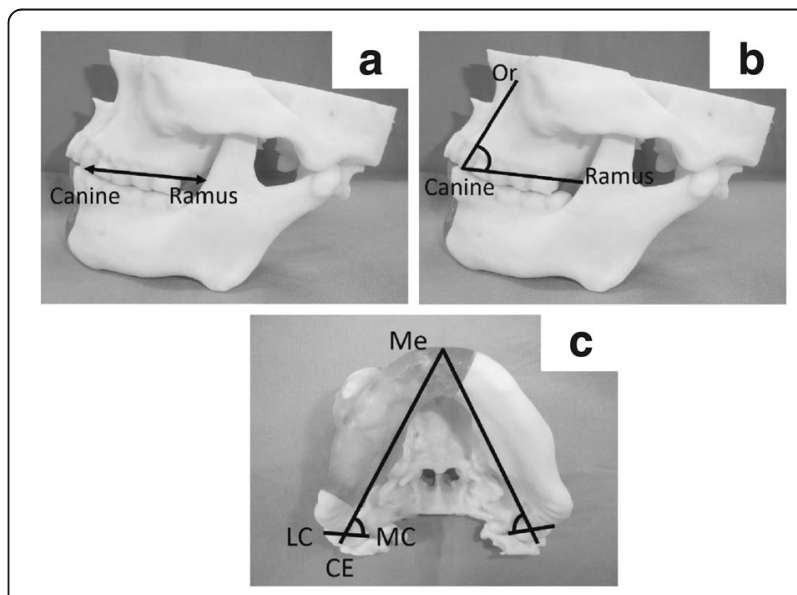

Fig. 2 a-c Measurements, length, and angle. a Length, ramus to maxillary canine, b Angle, Or-Canine-Ramus, c Angle, Me-CE and LC-MC 
Table 1 Measurement results

\begin{tabular}{|c|c|c|c|c|c|c|c|c|c|c|c|c|c|c|c|}
\hline \multirow[b]{3}{*}{ Case } & \multirow[b]{3}{*}{ Diagnosis } & \multirow[b]{3}{*}{ Age } & \multirow[b]{3}{*}{ Gender } & \multicolumn{4}{|c|}{$\begin{array}{l}\text { Length, ramus to maxillary } \\
\text { canine }\end{array}$} & \multicolumn{4}{|c|}{$\begin{array}{l}\text { Angle, Or-Canine- } \\
\text { Ramus }\end{array}$} & \multicolumn{4}{|c|}{$\begin{array}{l}\text { Angle, Me-CE and } \\
\text { LC-MC }\end{array}$} \\
\hline & & & & \multicolumn{2}{|c|}{$\begin{array}{l}\text { Before } \\
\text { simulation }\end{array}$} & \multicolumn{2}{|c|}{$\begin{array}{l}\text { After } \\
\text { simulation }\end{array}$} & \multicolumn{2}{|c|}{$\begin{array}{l}\text { Before } \\
\text { simulation }\end{array}$} & \multicolumn{2}{|c|}{$\begin{array}{l}\text { After } \\
\text { simulation }\end{array}$} & \multicolumn{2}{|c|}{$\begin{array}{l}\text { Before } \\
\text { simulation }\end{array}$} & \multicolumn{2}{|c|}{$\begin{array}{l}\text { After } \\
\text { simulation }\end{array}$} \\
\hline & & & & $\mathrm{R}(\mathrm{mm})$ & $L(m m)$ & $\mathrm{R}(\mathrm{mm})$ & $L(\mathrm{~mm})$ & $\mathrm{R}\left({ }^{\circ}\right)$ & $L\left({ }^{\circ}\right)$ & $\mathrm{R}\left({ }^{\circ}\right)$ & $L\left({ }^{\circ}\right)$ & $\mathrm{R}\left({ }^{\circ}\right)$ & $L\left({ }^{\circ}\right)$ & $\mathrm{R}\left({ }^{\circ}\right)$ & $L\left({ }^{\circ}\right)$ \\
\hline 1 & Mandibular ameloblastoma & 29 & Male & - & 53.5 & - & 53.5 & - & 68 & - & 68 & 78 & 86 & 78 & 86 \\
\hline 2 & Mandibular myxoma & 49 & Male & - & 53 & - & 53 & - & 64.5 & - & 64.5 & 68 & 71 & 68 & 71 \\
\hline 3 & Jaw deformity (mandibular prognathism) & 23 & Female & 46 & 48 & 46 & 48 & 71 & 73 & 71 & 72.5 & 69 & 71 & 69 & 71 \\
\hline 4 & $\begin{array}{l}\text { Jaw deformity (mandibular prognathism } \\
\text { and asymmetry) }\end{array}$ & 25 & Female & 47 & 43 & 47 & 43 & 64 & 63 & 64 & 63 & 75.5 & 76 & 75.5 & 76 \\
\hline
\end{tabular}

results indicate that this method can solve the problems associated with previous methods, which required devices other than a $3 \mathrm{D}$ model and relied on uncertain positioning of the condyle based on the operator's visual estimates.

\section{Discussion}

Globally, customized metal plates for jaw deformation and reconstruction are made with CAD/CAM based on preoperative computer simulations [5-7]. However, in Japan, only premade reconstructive plates can be used in patients. Most of the commercially available system is usefulness for operator who has a certain level of technique, but it is difficult for inexperienced operator to add image anatomical structure. Actually, young operator simulates for the operation with $3 \mathrm{D}$ model, to easily and deeply understand and operate safely. Use of full-scale $3 \mathrm{D}$ models facilitates not only a shorter, more precise operation as a result of a realistic pre-operation simulation, but enables a better grasp of the extent of bone movement and illustrates more ideal occlusion. 3D models would also enable the construction of temporary crowns and the fabrication of operation plates before surgery. In other institution, they used a magnet for condylar placement. This method is easier than our method. However, our method has higher accuracy and is cheaper than a magnet method.

Anatomically, the position of the mandible with respect to the maxilla is maintained only by ligaments. If the proximal bone fragment that includes the ramus detaches, the force of dislocation or rotation may cause postoperative jaw deformity or progressive condylar resorption [8]. Therefore, errors in preoperative simulations can affect the patient's postoperative oral function.

In the present study, we demonstrated that $3 \mathrm{D}$ models manufactured using our method can be applied to simulations and fully restore the position of the condyle without the need for special devices. The bending of metal plates can also be performed in this state. We plan to apply this method to many patients and examine the surgical precision using superimposition on postoperative CT.

\section{Conclusions}

3D model should have been used with this technique of condyle repositioning method for simulation of reconstruction and orthognathic surgery case. The novel repositioning method appears to be a simple and efficient way to correct condylar position.

\section{Abbreviations}

3D: Three-dimensional; CAD/CAM: Computer-aided design/computer-aided manufacturing; CE: Endpoint of the condyle; CT: Computed tomography; LC: Lateral point on the condyle; Me: Base of the mentum; Or: Inferior edge of the orbit; SSRO: Sagittal split ramus osteotomy

\section{Acknowledgements}

We would like to thank the members of the Tokyo Dental College Suidobashi Hospital for their cooperation.

\section{Funding}

None

\section{Availability of data and materials}

All data generated or analysed during this study are included in this published article.

\section{Authors' contributions}

KS participated in the design of the study and coordination of the study. YK and MK and YK worked in the data collection and analysis. SM and KO participated in the writing and helped to draft the manuscript. SA and MT participated in the design of the study and revision. AK participated in the study design and correction of the manuscript and coordination. The authors read and approved the final manuscript.

\section{Authors' information}

KS is D.D.S., Ph.D., and FIBCSOMS.

\section{Ethics approval and consent to participate}

The study was approved by the ethics committee of Tokyo Dental College (No. 646) (Tokyo, Japan).

Consent for publication

Not applicable

Competing interests

The authors declare that they have no competing interests.

\section{Publisher's Note}

Springer Nature remains neutral with regard to jurisdictional claims in published maps and institutional affiliations.

\section{Author details}

${ }^{1}$ Department of Oral Pathobiological Science and Surgery, Tokyo Dental College, 2-9-18 Kanda Misaki-cho, Chiyoda-ku, Tokyo, Japan. ${ }^{2}$ Oral Health 
Science Center, Tokyo Dental College, 2-9-18 Kanda Misaki-cho, Chiyoda-ku, Tokyo, Japan. ${ }^{3}$ Department of Anatomy, Tokyo Dental College, 2-9-18 Kanda Misaki-cho, Chiyoda-ku, Tokyo, Japan. ${ }^{4}$ Department of Oral and Maxillofacial Surgery, Tokyo Dental College, 2-9-18 Kanda Misaki-cho, Chiyoda-ku, Tokyo, Japan.

Received: 9 January 2018 Accepted: 14 February 2018

Published online: 05 March 2018

\section{References}

1. Katsumi Y, Sugahara K, Matsunaga S, Odaka K, Mitomo K, Abe S et al (2016) Planning for orthognathic surgery at medical fabrication laboratory in Tokyo Dental College (Fab Lab TDC): clinical application of full-scale-model made by 3-dimensional ink jet printer for orthognathic surgery. Oral Science Japan 2016:9-11

2. Ayoub AF, Rehab M, O'neil M, Khambay B, Ju X, Barbenel J et al (2014) A novel approach for planning orthognathic surgery: the integration of dental casts into three-dimensional printed mandibular models. J Oral Maxillofac Surg 43:454-459

3. Yuan P, Mai H, Li J, Ho DC, Lai Y, Liu S et al (2017) Design, development and clinical validation of computer-aided surgical simulation system for streamlined orthognathic surgical planning. Int J Comput Assist Radiol Surg 12:2129-2143

4. Mayuka N, Katsuhiko S, Kazutaka K (2016) The characteristics of mandibula morphology in facial asymmetry by using axial cephalometric radiographs. Nihon Univ J Oral Sci U 42:4-54

5. Suojanen J, Leikola J, Stoor P (2016) The use of patient-specific implants in orthognathic surgery: a series of 32 maxillary osteotomy patients. J Craniomaxillofac Surg 44:1913-1916

6. Cornelius CP, Smolka W, Giessler GA, Wilde F, Probst FA (2015) Patientspecific reconstruction plates are the missing link in computer-assisted mandibular reconstruction: a showcase for technical description. J Craniomaxillofac Surg 43:624-629

7. Wilde F, Hanken H, Probst F, Schramm A, Heiland M, Cornelius CP (2015) Multicenter study on the use of patient-specific CAD/CAM reconstruction plates for mandibular reconstruction. Int I Comput Assist Radiol Surg 10: 2035-2051

8. Yuki M, Koichi N, Machiko K, Hiroshi Y, Kazuto K, Kiyoshi H (2014) The comparative study of two types of condylar positioning systems for double-jaw orthognathic surgery. J Jaw Deform 24:203-210

\section{Submit your manuscript to a SpringerOpen ${ }^{\circ}$ journal and benefit from:}

- Convenient online submission

- Rigorous peer review

- Open access: articles freely available online

- High visibility within the field

- Retaining the copyright to your article 